\title{
The residues of glyphosate in grain and straw of spring wheat and germination of grain after pre-harvest application of herbicide
}

\section{Pozostałości glifosatu w ziarnie i słomie oraz zdolność kiełkowania ziarna pszenicy jarej po zastosowaniu herbicydu w postaci cieczy jonowych w zabiegu przedżniwnym}

\author{
Katarzyna Marcinkowska*
}

\section{Summary}

The influence of six herbicidal ionic liquids include glyphosate [ $\mathrm{N}$-(phosphonomethyl)glycine] using in spring wheat as the preharvest application (BBCH 87) was studied in 2013-2014. Tested compounds had not negative impact on seed germinative energy and germination capacity. There were not residues of glyphosate and its main metabolite AMPA [2-amino-3-(5-methyl-3-oxo-1,2-oxazol-4 -yl) propionic acid] in grains of spring wheat. Residues of these compounds were below the limit of quantification $(<0.01 \mathrm{mg} / \mathrm{kg})$. The presence of AMPA in the straw was not detected, while the residues of glyphosate were negligible $(0.01-0.02 \mathrm{mg} / \mathrm{kg})$.

Key words: herbicidal ionic liquids; glyphosate; residues; germinative energy; germination capacity; desiccation

\section{Streszczenie}

W latach 2013-2014 badano wpływ 6 herbicydowych cieczy jonowych zawierających glifosat [N-(fosfonometylo)glicyna] stosowanych w pszenicy jarej w fazie dojrzałości woskowej twardej (BBCH 87). Nie stwierdzono negatywnego wpływu badanych związków na energię i zdolność kiełkowania ziarna. Nie stwierdzono również zanieczyszczeń ziarna glifosatem i jego głównym metabolitem AMPA [kwas 2-amino-3-(5-metylo-3-okso-1,2-oksazol-4-ilo)propionowy]. Pozostałości tych związków były poniżej granicy oznaczalności metody $(<0,01 \mathrm{mg} / \mathrm{kg})$. W słomie nie wykryto obecności AMPA, natomiast pozostałości glifosatu były znikome $(0,01-0,02 \mathrm{mg} / \mathrm{kg})$.

Słowa kluczowe: herbicydowe ciecze jonowe; glifosat; pozostałości; energia kiełkowania; zdolność kiełkowania; desykacja

\footnotetext{
Instytut Ochrony Roślin - Państwowy Instytut Badawczy

Zakład Badania Środków Ochrony Roślin

Władysława Węgorka 20, 60-318 Poznań

*corresponding author: k.marcinkowska@iorpib.poznan.pl
} 


\section{Wstęp / Introduction}

Równomierne dojrzewanie łanu zbóż jest jednym $\mathrm{z}$ istotnych warunków sprawnego przeprowadzenia zbioru plonu. Jest ono uzależnione w dużym stopniu od wyboru stanowiska pod uprawę, przebiegu warunków atmosferycznych oraz skuteczności zastosowanych metod ochrony przed zachwaszczeniem. Chwasty, które nie zostały zwalczone w początkowych fazach wzrostu zbóż, lub które pojawiły się na plantacji jako tak zwane zachwaszczenie wtórne, mogą w znacznym stopniu zakłócać naturalne zasychanie roślin i utrudniać, a w skrajnych przypadkach nawet uniemożliwiać zbiór ziarna. W takiej sytuacji korzystnym rozwiązaniem może być zastosowanie glifosatu w okresie 10-14 dni przed planowanym zbiorem, gdy wilgotność ziarna wynosi 20-30\%. Skutkiem tego zabiegu jest nie tylko zasychanie chwastów, ale także dosuszenie łanu zbóż w wyniku czego ułatwione są prace żniwne. Ziarno zebrane $\mathrm{z}$ takich plantacji nie powinno być przeznaczone na materiał siewny $\mathrm{z}$ uwagi na możliwość obniżenia zdolności kiełkowania (Mystek i Szukała 2007; Jaskulski i Jaskulska 2011).

Glifosat [N-(fosfonometylo)glicyna] jest pochodną kwasu fosfonowego, w której jeden atom wodoru grupy metylowej bezpośrednio połączonej $\mathrm{z}$ fosforem został zastąpiony przez glicynę. Występuje on w postaci kwasu, soli amonu, sodu, potasu, soli izopropyloamonu oraz jako sól trimetylosulfonu (Müller i wsp. 2014). Jest to herbicyd nieselektywny przeznaczony do zwalczania szerokiego spektrum chwastów na polach uprawnych i może być stosowany przed wschodami niektórych roślin uprawnych, krótko przed ich zbiorem lub po zbiorach, ale przed rozpoczęciem upraw pożniwnych. Ponadto glifosat stosowany jest w uprawach sadowniczych, podczas likwidacji ugorów i odłogów oraz na terenach nieużytkowanych rolniczo (Tomlin 2009). Przedmiotem prezentowanych badań były herbicydowe ciecze jonowe zawierające glifosat. Pierwsze doniesienie o herbicydowych cieczach jonowych zostało opublikowane w 2011 roku i dotyczyło pochodnych fenoksykwasów (Pernak i wsp. 2011). Herbicydowe ciecze jonowe (herbicidal ionic liquids - HILs) są solami o temperaturze topnienia poniżej $100^{\circ} \mathrm{C}$ posiadającymi jon herbicydowy (Pernak i wsp. 2011). Jedną $z$ istotnych zalet HILs jest fakt, że przez odpowiedni dobór kationu można modelować związek w taki sposób, by otrzymać ciecz jonową o pożądanych właściwościach fizykochemicznych i odpowiedniej aktywności chwastobójczej.

Ciecze jonowe będace przedmiotem niniejszej pracy zbudowane są $\mathrm{z}$ anionu herbicydowego (glifosat) oraz różnych kationów, w tym pochodzenia naturalnego. Większość z tych nowych związków chemicznych charakteryzuje się korzystnymi właściwościami powierzchniowo czynnymi, co umożliwia dobre zwilżenie opryskiwanych roślin. Co więcej herbicydowe ciecze jonowe są związkami o znikomej lotności, czyli wyeliminowane jest ryzyko znoszenia substancji czynnej na sąsiednie pola przez parowanie (Cojocaru i wsp. 2013). Brak parowania cieczy jonowych ułatwia i czyni bardziej bezpiecznym także ich magazynowanie, transportowanie i aplikację.
Celem prezentowanych badań była ocena wpływu nowych form glifosatu w postaci herbicydowych cieczy jonowych stosowanych $\mathrm{w}$ zabiegu przedżniwnym na pozostałości tego herbicydu i jego głównego metabolitu AMPA [kwas 2-amino-3-(5-metylo-3-okso-1,2-oksazol-4-ilo)propionowy] w ziarnie i słomie pszenicy jarej oraz na energię i zdolność kiełkowania ziarna.

\section{Materiały i metody / Materials and methods}

Badania polowe prowadzono w latach 2013 i 2014 w Polowej Stacji Doświadczalnej Instytutu Ochrony Roślin - Państwowego Instytutu Badawczego (IOR - PIB) w Winnej Górze na poletkach o powierzchni $12,5 \mathrm{~m}^{2}$, w układzie bloków losowanych kompletnych, w 4 powtórzeniach. Herbicydowe ciecze jonowe oraz preparaty porównawcze aplikowano jako zabieg przedżniwny (BBCH 87) w uprawie pszenicy jarej odmiany Brawura. Nowe formy glifosatu (rys. 1) zsyntezowano na Wydziale Technologii Chemicznej Politechniki Poznańskiej. Charakterystykę herbicydowych cieczy jonowych przedstawiono w tabeli 1. Jako preparaty porównawcze stosowano glifosat w postaci soli potasu - o czystości technicznej Glif-K (zsyntezowana na Politechnice Poznańskiej) oraz komercyjny herbicyd Roundup 360 SL - Glif-IPA (360 g glifosatu w formie soli izopropyloamonu w 11 preparatu; Monsanto Europe, Belgia).<smiles>[R][N+]([R])([R])C</smiles>

Rys. 1. Struktura herbicydowej cieczy jonowej zawierającej anion glifosatu

Fig. 1. The structure of the herbicidal ionic liquid containing the glyphosate anion

Tabela 1. Budowa kationu w badanych herbicydowych cieczach jonowych

Table 1. Cation's structure of tested herbicidal ionic liquids

\begin{tabular}{l|ccc}
\hline \multirow{2}{*}{\multicolumn{1}{c|}{ HILs }} & \multicolumn{3}{|c}{ Kation - Cation } \\
\cline { 2 - 4 } & $\mathrm{R}^{\mathrm{l}}$ & $\mathrm{R}^{2}$ & $\mathrm{R}^{3}$ \\
\hline [DDA][Glif] & $\mathrm{CH}_{3}$ & $\mathrm{C}_{10} \mathrm{H}_{21}$ & $\mathrm{C}_{10} \mathrm{H}_{21}$ \\
[DecEtMor][Glif] & $\mathrm{CH}_{3}$ & $\mathrm{C}_{10} \mathrm{H}_{21}$ & - \\
[DADMA][Glif] & $\mathrm{CH}_{3}$ & $\mathrm{CH}_{2} \mathrm{CH}=\mathrm{CH}_{2}$ & $\mathrm{CH}_{2} \mathrm{CH}=\mathrm{CH}_{2}$ \\
[Etq O-12][Glif] & $\mathrm{CH}_{2} \mathrm{CH}_{2} \mathrm{OH}$ & $\mathrm{CH}_{2} \mathrm{CH}_{2} \mathrm{OH}$ & Alkil $^{\mathrm{a}}$ \\
[Etq C-12][Glif] & $\mathrm{CH}_{2} \mathrm{CH}_{2} \mathrm{OH}$ & $\mathrm{CH}_{2} \mathrm{CH}_{2} \mathrm{OH}$ & Alkil $^{\text {b }}$ \\
[Arq 2HT][Glif] & $\mathrm{CH}_{3}$ & $\mathrm{Alkil}^{\mathrm{c}}$ & Alkil $^{\mathrm{c}}$
\end{tabular}

HILs - herbicydowe ciecze jonowe - herbicidal ionic liquids

${ }^{a}$ Oleyl - mieszanina nienasyconych podstawników alkilowych - mixture of unsaturated alkyl substituents:

$\mathrm{C}_{12}-5 \%, \mathrm{C}_{14}-1 \%, \mathrm{C}_{16}-14 \%, \mathrm{C}_{18}-80 \%$

${ }^{\mathrm{b}} \mathrm{Coco}$ - mieszanina nasyconych podstawników alkilowych - mixture of saturated alkyl substituents:

$\mathrm{C}_{8}-5 \%, \mathrm{C}_{10^{-}}-6 \%, \mathrm{C}_{12}-50 \%, \mathrm{C}_{14}-19 \%, \mathrm{C}_{16}-14 \%, \mathrm{C}_{18}-10 \%$

chydrogenated tallow - mieszanina nasyconych podstawników alkilowych

- mixture of saturated alkyl substituents:

$\mathrm{C}_{12}-1 \%, \mathrm{C}_{14}-4 \%, \mathrm{C}_{16}-31 \%, \mathrm{C}_{18}-64 \%$ 
Przygotowano roztwory wodne dla badanych środków z wyjątkiem [Arq 2HT][Glif], który rozpuszczono w mieszaninie wody i etanolu w stosunku objętościowym 1 : 1 . Dawka glifosatu wynosiła 1440 g na 1 ha. Zabiegi wykonano przy użyciu opryskiwacza plecakowego firmy APORO (Polska) wyposażonego w rozpylacze TeeJet ${ }^{\circledR}$ DG110/02 VS (TeeJet Technologies, USA). Wydatek cieczy użytkowej wynosił 200 1/ha, przy ciśnieniu $3 \times 10^{5} \mathrm{~Pa}$.

\section{Badanie energii i zdolności kiełkowania ziarna pszenicy}

Energię i zdolność kiełkowania oceniano w warunkach laboratoryjnych. Na płytki Petriego wyłożono po 100 ziaren pszenicy pobranych $\mathrm{z}$ poletek doświadczalnych. Nasiona umieszczono na bibule filtracyjnej, nawilżonej uprzednio wodą destylowaną. Następnie płytki z ziarnem umieszczono w fitotronie Rumed ${ }^{\circledR} 1501$ firmy Rubarth Apparate $\mathrm{GmbH}$ (Niemcy) w temperaturze $20^{\circ} \mathrm{C}$, przy wilgotności $60 \%$ i fotoperiodzie wynoszącym 14/10 dnia/nocy. Bibułę zwilżano w razie potrzeby. Po 5 dniach określano energię kiełkowania, a po upływie 8 dni określano zdolność kiełkowania zgodnie ze standardami ISTA (International Seed Testing Association, Oznaczenie 2013).

Uzyskane wyniki poddano analizie statystycznej. Warunek jednorodności wariancji został spełniony tylko w przypadku energii kiełkowania w 2013 roku. Dla tego doświadczenia, po przeprowadzeniu analizy wariancji, zastosowano wielokrotny test post hoc Tukeya, przy $\alpha=0,05$. Dla pozostałych eksperymentów przeprowadzono nieparametryczny test Kruskala-Wallisa.

\section{Pozostałości glifosatu i AMPA w ziarnie oraz słomie}

Oznaczenie pozostałości glifosatu i jego metabolitu AMPA wykonano przy zastosowaniu tandemowego spektrometru mas sprzężonego $\mathrm{z}$ chromatografem cieczowym (LC/MS/MS - liquid chromatography coupled with tandem mass spectrometry). Analizę przeprowadzono w Terenowej Stacji Doświadczalnej IOR - PIB w Białymstoku.

$\mathrm{Z}$ ziarna zebranego $\mathrm{z}$ poletek, na których stosowano nowe formy glifosatu $\mathrm{w}$ zabiegu przedżniwnym, pobrano losowo próbki, które przechowywano w temperaturze $-20^{\circ} \mathrm{C}$ przez okres dwóch miesięcy. Następnie próby rozmrożono i rozdrobniono. Do zhomogenizowanych próbek dodano wodę, $0,1 \%$ kwas mrówkowy oraz roztwór znakowanego izotopowo $\left({ }^{13} \mathrm{C}^{15} \mathrm{~N}\right)$-glifosatu, jako wzorca wewnętrznego.

Analizę instrumentalną wykonano przy użyciu chromatografu cieczowego Eksigent Ultra LC-100 sprzężonego ze spektrometrem mas QTRAP 6500 (AB Sciex Instruments, Foster City, CA).

Separację przeprowadzono w kolumnie Zorbax Eclipse Plus C18 Rapid Resolution HP (Agilent Technologies) $(100 \mathrm{~mm} \times 2,1 \mathrm{~mm}, 1,8 \mu \mathrm{m})$. Natomiast detekcję przeprowadzono stosując ujemną jonizację poprzez rozpylanie w polu elektrycznym (ESI - electrospray ionization) w specyficznych warunkach fragmentacji MS/MS.

Granicę wykrywalności metody zarówno dla glifosatu, jak i AMPA określono na poziomie $0,005 \mathrm{mg} / \mathrm{kg}$, natomiast granica oznaczalności wynosiła $0,01 \mathrm{mg} / \mathrm{kg}$.

\section{Wyniki i dyskusja / Results and discussion}

Przedżniwne stosowanie glifosatu jest uzasadnione w szczególnych przypadkach, np. gdy brak możliwości naturalnego dojrzewania łanu, najczęściej na skutek niesprzyjających warunków atmosferycznych. W literaturze pojawiają się informacje na temat negatywnego wpływu tego zabiegu na jakość ziarna, zwłaszcza na zdolność kiełkowania. W badaniach prowadzonych przez Beig i wsp. (2003) wykazano, że zabieg przedżniwny zmniejszył zdolność kiełkowania ziarna pszenicy. Odmienne wyniki uzyskano $\mathrm{w}$ dwuletnich badaniach własnych stosując herbicydowe ciecze jonowe zawierające glifosat w uprawie pszenicy jarej.

\section{Energia i zdolność kiełkowania ziarna}

Ziarno pszenicy jarej pozyskano z roślin traktowanych różnymi formami glifosatu $\mathrm{w}$ fazie dojrzałości woskowej twardej.

W tabeli 2. przedstawiono wyniki analizy wariancji dla doświadczenia prowadzonego w 2013 roku. W przypadku zdolności kiełkowania nie zostało spełnione założenie dotyczące rozkładu normalnego, dlatego wykonano test nieparametryczny (tab. 3), który wykazał brak istotnych różnic między kombinacjami.

Tabela 2. Analiza wariancji - energia kiełkowania (2013 r.)

Table 2. Analysis of variance - germinative energy (2013)

\begin{tabular}{|c|c|c|c|c|c|c|}
\hline Zmienność - Variability & Df & SS & MS & $\mathrm{F}$ & $\mathrm{p}$ & \\
\hline Związek - Treatment & 9 & 0,27 & 0,02 & 2,573 & $2,78 \times 10^{-2}$ & * \\
\hline Blok - Block & 3 & 0,05 & 0,01 & 1,325 & 0,287 & \\
\hline Błąd - Error & 27 & 0,31 & 0,01 & & & \\
\hline Całkowita - Total & 39 & 0,63 & & & & \\
\hline Kod istotności - Code of significance & & ‘***’ & 0,01 & $5 \because 0$ & 1 & \\
\hline
\end{tabular}

Df - stopnie swobody - degrees of freedom, SS - suma kwadratów - sum of squares, MS - średni kwadrat - mean square, $\mathrm{F}$ - wartość statystyki $\mathrm{F}$ - F value/F statistic, $\mathrm{p}$ - prawdopodobieństwo testowe - p-value/probability value 
Tabela 3. Analiza statystyczna - zdolność kiełkowania (2013 r.)

Table 3. Statistical analysis - germination capacity (2013)

\begin{tabular}{|c|c|c|c|}
\hline Zmienność - Variability & Df & $\chi^{2}$ & $\mathrm{p}$ \\
\hline Związek - Treatment & 9 & 14,498 & 0,106 \\
\hline Kod istotności - Code of significance & & 01 ' $* * 0$ & \\
\hline
\end{tabular}

Df - stopnie swobody - degrees of freedom, $\chi^{2}$ - wartość statystyki chi-kwadrat - chi-square,

$\mathrm{p}$ - prawdopodobieństwo testowe $-\mathrm{p}$-value/probability value

Tabela 4. Analiza statystyczna - energia i zdolność kiełkowania (2014 r.)

Table 4. Statistical analysis - germinative energy and germination capacity (2014)

\begin{tabular}{|c|c|c|c|}
\hline Zmienność - Variability & Df & $\chi^{2}$ & $\mathrm{p}$ \\
\hline $\begin{array}{l}\text { Związek - Treatment } \\
\text { (energia kiełkowania) - (germinative energy) }\end{array}$ & 9 & 4,671 & 0,862 \\
\hline $\begin{array}{l}\text { Związek - Treatment } \\
\text { (zdolność kiełkowania) - (germination capacity) }\end{array}$ & 9 & 5,695 & 0,770 \\
\hline Kod istotności - Code of significance & 0 & 1 ' $*$ ' & \\
\hline
\end{tabular}

Df - stopnie swobody - degrees of freedom, $\chi^{2}$ - wartość statystyki chi-kwadrat - chi-square,

$\mathrm{p}$ - prawdopodobieństwo testowe - $\mathrm{p}$-value/probability value

Tabela 5. Wpływ herbicydowych cieczy jonowych zawierających glifosat stosowanych w zabiegu przedżniwnym na energię i zdolność kiełkowania pszenicy jarej [\%]

Table 5. The impact of herbicidal ionic liquids based on glyphosate used as pre-harvest applications on germinative energy and germination capacity of spring wheat $[\%]$

\begin{tabular}{l|cc|cc}
\hline \multirow{2}{*}{$\begin{array}{c}\text { Obiekty } \\
\text { Treatments }\end{array}$} & $\begin{array}{c}\text { Energia kiełkowania } \\
\text { Germinative energy }\end{array}$ & $\begin{array}{c}\text { Zdolność kiełkowania } \\
\text { Germination capacity }\end{array}$ & $\begin{array}{c}\text { Energia kiełkowania } \\
\text { Germinative energy }\end{array}$ & $\begin{array}{c}\text { Zdolność kiełkowania } \\
\text { Germination capacity }\end{array}$ \\
\cline { 2 - 5 } & \multicolumn{2}{c}{2013} & 914 \\
\hline (woda) - (water) & $88,8 \mathrm{ab}$ & $99,3 \mathrm{a}$ & $99,3 \mathrm{a}$ & $96,0 \mathrm{a}$ \\
(woda : etanol) & $87,0 \mathrm{~b}$ & $97,8 \mathrm{a}$ & $98,0 \mathrm{a}$ & $96,8 \mathrm{a}$ \\
(water : ethanol) & $97,5 \mathrm{ab}$ & $98,5 \mathrm{a}$ & $99,0 \mathrm{a}$ & $99,5 \mathrm{a}$ \\
[DDA][Glif] & $93,0 \mathrm{ab}$ & $98,8 \mathrm{a}$ & $99,0 \mathrm{a}$ & $97,5 \mathrm{a}$ \\
[DecEtMor][Glif] & $96,0 \mathrm{ab}$ & $98,8 \mathrm{a}$ & $99,3 \mathrm{a}$ & $97,5 \mathrm{a}$ \\
[DADMA][Glif] & $95,5 \mathrm{ab}$ & $98,0 \mathrm{a}$ & $98,5 \mathrm{a}$ & $98,0 \mathrm{a}$ \\
[Etq O-12][Glif] & $92,0 \mathrm{ab}$ & $98,5 \mathrm{a}$ & $98,5 \mathrm{a}$ & $97,0 \mathrm{a}$ \\
[Etq C-12][Glif] & $95,3 \mathrm{ab}$ & $97,8 \mathrm{a}$ & $97,8 \mathrm{a}$ & $97,3 \mathrm{a}$ \\
[Arq 2HT][Glif] & $98,8 \mathrm{a}$ & $99,0 \mathrm{a}$ & $99,3 \mathrm{a}$ & $99,3 \mathrm{a}$ \\
Glif-K & $95,8 \mathrm{ab}$ & $98,5 \mathrm{a}$ & $98,8 \mathrm{a}$ & $98,3 \mathrm{a}$ \\
Glif-IPA & & & \\
\hline
\end{tabular}

Wartości oznaczone tymi samymi literami nie różnią się istotnie przy $\alpha=0,05$

Values marked with the same letters do not differ significantly at $\alpha=0.05$

Najwyższą energię kiełkowania ziarna odnotowano na obiektach, na których stosowano glifosat w postaci soli potasu, natomiast najniższą na obiektach kontrolnych, na których rośliny traktowane były mieszaniną wody $\mathrm{i}$ etanolu. Najniższą zdolnością kiełkowania wykazały się ziarna pobrane $\mathrm{z}$ obiektu kontrolnego (woda), a najwyższą ziarna pozyskane $\mathrm{z}$ roślin traktowanych związkiem [DDA][Glif], jednakże uzyskane wyniki nie różniły się istotnie statystycznie (tab. 5).

W roku 2014 do analizy statystycznej zastosowano testy nieparametryczne, które nie wykazały statystycznie istotnych różnic pomiędzy obiektami (tab. 4).

Uzyskane wyniki w przedziale od 97,8 do $100 \%$ świadczą, iż desykacja łanu pszenicy nowymi formami glifosatu nie wpływała negatywnie na energię i zdolność kiełkowania ziarna.

Inni autorzy wykazali, iż glifosat wpłynął negatywnie na zdolność kiełkowania ziarna, wschody i wzrost siewek pszenicy ozimej (Jaskulski i Jaskulska 2011). Yenish i Young (2000) informowali również o inhibicyjnym wpływie $N$-(fosfonometylo)glicyny na zdolność kiełkowania nasion. Jednakże zwrócili uwagę, że decyduje o tym między innymi termin zabiegu. W przypadku desykacji w fazie dojrzewania mlecznej pszenicy jarej, uzyskano spadek energii kiełkowania od 2 do $46 \%$ w porównaniu do kombinacji kontrolnej (Yenish i Young 2000). W literaturze pojawiają się sprzeczne informacje na temat zdolności kiełkowania nasion roślin, których łan desykowano glifosatem. Jednak zdecydowana większość autorów pisze, 
iż aplikacja glifosatu w odpowiednim terminie (faza dojrzałości woskowej ziarna), nie przyczynia się do obniżenia zdolności kiełkowania nasion (Darwent i wsp. 1994). Potwierdzają to także badania własne, które ponadto wykazały, że zarówno handlowy herbicyd i $\mathrm{N}$-(fosfonometylo)glicyna $\mathrm{w}$ postaci soli potasu oraz herbicydowych cieczy jonowych, aplikowane zgodnie z zaleceniami, nie wpływały negatywnie na kiełkowanie ziarna pszenicy jarej.

\section{Pozostałości glifosatu i AMPA w ziarnie oraz słomie}

Badania pozostałości środków ochrony roślin są jednym z najważniejszych elementów ochrony zdrowia ludzi przed ich niepożądanym działaniem. Z tego względu pozostałości te są kontrolowane i porównywane do najwyższych dopuszczalnych poziomów pozostałości (NDP), przed wprowadzeniem żywności do obiegu (Rozporządzenie 2005; Ustawa 2006). Pożądane jest, aby płody rolne nie zawierały zanieczyszczeń bądź były one poniżej NDP (Łozowicka i wsp. 2012).

Zgodnie z Dyrektywą Komisji 2005/70/WE z dnia 20 października 2005 r. najwyższy dopuszczalny poziom glifosatu dla ziarna pszenicy wynosi $10 \mathrm{mg} / \mathrm{kg}$.

Badania pozostałości glifosatu i jego metabolitu AMPA W ziarnie po zastosowaniu herbicydowych cieczy jonowych oraz standardu wykonano techniką LC/MS/MS (liquid chromatography/mass spectrometry/mass spectrometry). Wyniki dla ziarna pobranego z doświadczeń, w których łan pszenicy desykowano nowymi formami glifosatu przedstawiono w tabeli 6 .

Tabela 6. Pozostałości glifosatu i AMPA w ziarnie pszenicy jarej po zastosowaniu herbicydu w postaci cieczy jonowych w zabiegu przedżniwnym

Table 6. The residues of glyphosate and AMPA in the grain of spring wheat after pre-harvest application of herbicidal ionic liquids

\begin{tabular}{l|cc|cc}
\hline \multirow{2}{*}{$\begin{array}{c}\text { Obiekty } \\
\text { Treatments }\end{array}$} & \multicolumn{3}{|c}{ Pozostałości-Residues [mg/kg] } \\
\cline { 2 - 5 } & \multicolumn{2}{|c}{2013} & \multicolumn{2}{c}{2014} \\
\cline { 2 - 5 } & glifosat & AMphosate & \multicolumn{2}{c}{$\begin{array}{c}\text { glifosat } \\
\text { glyphosate }\end{array}$} \\
\hline [DDA][Glif] & $<0,01$ & $<0,01$ & $<0,01$ & $<0,01$ \\
[DecEtMor][Glif] & $<0,01$ & $<0,01$ & $<0,01$ & $<0,01$ \\
[DADMA][Glif] & $<0,01$ & $<0,01$ & $<0,01$ & $<0,01$ \\
[Etq O-12][Glif] & $<0,01$ & $<0,01$ & $<0,01$ & $<0,01$ \\
[Etq C-12][Glif] & $<0,01$ & $<0,01$ & $<0,01$ & $<0,01$ \\
[Arq 2HT][Glif] & $<0,01$ & $<0,01$ & $<0,01$ & $<0,01$ \\
Glif-K & $<0,01$ & $<0,01$ & $<0,01$ & $<0,01$ \\
Glif-IPA & 0,01 & $<0,01$ & $<0,01$ & $<0,01$ \\
\hline
\end{tabular}

AMPA - kwas 2-amino-3-(5-metylo-3-okso-1,2-oksazol-4-ilo)propionowy - 2-amino-3-(5-methyl-3-oxo-1,2-oxazol-4-yl)propionic acid

Badania prowadzono w dwóch sezonach wegetacyjnych. Z przeprowadzonych badań wynika, że zawartość glifosatu oraz AMPA w ziarnie pszenicy była poniżej granicy oznaczalności metody dla wszystkich badanych obiektów z jednym wyjątkiem. Dla komercyjnego herbicydu uzyskano wynik $0,01 \mathrm{mg} / \mathrm{kg}$ dla próby ziarna pobranej w 2013 roku. Wartość tej pozostałości jest 100-krotnie mniejsza niż najwyższy, dopuszczalny poziom glifosatu dla pszenicy.

Tabela 7. Pozostałości glifosatu i AMPA w słomie pszenicy jarej po zastosowaniu herbicydu w postaci cieczy jonowych w zabiegu przedżniwnym

Table 7. The residues of glyphosate and AMPA in the straw of spring wheat after pre-harvest application of herbicidal ionic liquids

\begin{tabular}{l|cc}
\hline \multirow{2}{*}{$\begin{array}{c}\text { Obiekty } \\
\text { Treatments }\end{array}$} & \multicolumn{2}{|c}{ Pozostałości-Residues [mg/kg] } \\
\cline { 2 - 3 } & $\begin{array}{c}\text { glifosat } \\
\text { glyphosate }\end{array}$ & AMPA \\
\hline [DDA][Glif] & 0,01 & $<0,01$ \\
[DecEtMor][Glif] & 0,01 & $<0,01$ \\
[DADMA][Glif] & 0,03 & $<0,01$ \\
[Etq O-12][Glif] & 0,01 & $<0,01$ \\
[Etq C-12][Glif] & 0,01 & $<0,01$ \\
[Arq 2HT][Glif] & 0,03 & $<0,01$ \\
Glif-K & $<0,01$ & $<0,01$ \\
Glif-IPA & 0,03 & $<0,01$ \\
\hline
\end{tabular}

AMPA - kwas 2-amino-3-(5-metylo-3-okso-1,2-oksazol-4-ilo)propionowy - 2-amino-3-(5-methyl-3-oxo-1,2-oxazol-4-yl)propionic acid

W 2013 roku badano także pozostałości glifosatu i jego głównego metabolitu w słomie. Wyniki tego doświadczenia zamieszczono $\mathrm{w}$ tabeli 7 . W słomie nie wykryto obecności AMPA. Glifosat oznaczono dla wszystkich cieczy jonowych oraz komercyjnego herbicydu. Ich wartości wahały się od 0,01 do 0,03 ppm.

\section{Wnioski / Conclusions}

1. Zastosowanie herbicydowych cieczy jonowych zawierających glifosat, a także komercyjnych form tego herbicydu w okresie dojrzałości woskowej twardej (BBCH 87) pszenicy jarej nie wpłynęło negatywnie na energię i zdolność kiełkowania ziarna.

2. Po zastosowaniu glifosatu w formie cieczy jonowych w zabiegu przedżniwnym w pszenicy jarej nie stwierdzono zanieczyszczeń ziarna tą substancją i jej głównym metabolitem AMPA. W słomie nie wykryto obecności AMPA, natomiast pozostałości glifosatu były znikome (0,01-0,02 ppm).

\section{Podziękowanie / Acknowledgements}

Podziękowania dla doktorantów z Politechniki Poznańskiej z grupy badawczej prof. dr. hab. inż. Juliusza Pernaka za przekazanie próbek herbicydowych cieczy jonowych do badań biologicznych. Autorka dziękuje także prof. dr hab. Bożenie Łozowickiej i dr Piotrowi Kaczyńskiemu za 
wykonanie analiz pozostałości glifosatu i jego metabolitu AMPA.
Badania wykonano w ramach badań statutowych BŚOR-11.

\section{Literatura / References}

Beig M.N., Darwent A.L., Harker K.N., O’Donovan J.T. 2003. Preharvest application of glyphosate after emergance and seeding growth of field pea (Pisum sativum). Weed Technology 17 (4): 655-665.

Cojocaru O.A., Shamshina J.L., Gurau G., Syguda A., Praczyk T., Pernak J., Rogers R.D. 2013. Ionic liquid forms of the herbicide dicamba with increased efficacy and reduced volatility. Green Chemistry 15 (8): 2110-2120.

Darwent A.L., Kikland K.J., Townley-Smith L., Harker K.N., Cessna A.J., Lukow O.M., Lefkovitch L.P. 1994. Effect of preharvest applications of glyphosate on the drying, yield and quality of wheat. Canadian Journal of Plant Science 74 (2): 221-230.

Dyrektywa Komisji 2005. Dyrektywa Komisji 2005/70/WE z dnia 20 października 2005 r. zmieniająca dyrektywy Rady 86/362/EWG, 86/363/EWG i 90/642/EWG w sprawie ustalania najwyższych dopuszczalnych poziomów pozostałości niektórych pestycydów odpowiednio w zbożach i niektórych produktach pochodzenia zwierzęcego i roślinnego, oraz na ich powierzchni. Dz. Urz. UE L 276/35 z 21.10.2005 r.

Jaskulski D., Jaskulska I. 2011. Wpływ glifosatu stosowanego przed zbiorem na kiełkowanie ziarna i wschody samosiewów pszenicy ozimej. [Effect of pre-harvest glyphosate application on grain germination and emergence of winter wheat self-sown plants]. Progress in Plant Protection/Postępy w Ochronie Roślin 51 (2): 927-931.

Łozowicka B., Hrynko I., Rutkowska E., Jankowska M., Kaczyński P., Janowicz T. 2012. Pozostałości środków ochrony roślin w owocach i warzywach z północno-wschodniej Polski (2008-2011). [Pesticide residues in fruit and vegetables from north-eastern Poland (2008-2011)]. Progress in Plant Protection/Postępy w Ochronie Roślin 52 (2): 423-430.

Müller K., Tiktak A., Dijkman T.J., Green S., Clothier B. 2014. Advances in pesticide risk reduction. p. 17-34. In: "Encyclopedia of Agriculture and Food Systems" (N.K. van Alfen, ed.). Academic Press, USA, 601 pp.

Mystek A., Szukała J. 2007. Wpływ desykantów na wartość siewną nasion łubinu. [Influence of desiccants on seeding value of lupine seeds]. Progress in Plant Protection/Postępy w Ochronie Roślin 47 (3): 216-219.

Oznaczenie zdolności kiełkowania 2013. p. 5. W: „Międzynarodowe przepisy oceny nasion / International Rules for Seed Testing”. Międzynarodowy Związek Oceny Nasion / International Seed Testing Association (ISTA), Bassersdorf, Szwajcaria, 88 ss.

Pernak J., Syguda A., Janiszewska D., Materna K., Praczyk T. 2011. Ionic liquids with herbicidal anions. Tetreahedron 67 (26): $4838-4844$

Rozporządzenie Parlamentu Europejskiego i Rady 2005. Rozporządzenie (WE) nr 396/2005 Parlamentu Europejskiego i Rady z dnia 23 lutego 2005 r. w sprawie najwyższych dopuszczalnych poziomów pozostałości pestycydów w żywności i paszy pochodzenia roślinnego i zwierzęcego oraz na ich powierzchni, zmieniające dyrektywę Rady 91/414/EWG. Dz. Urz. L 70 z 16.03.2005 r.: 1-16.

Tomlin C.D.S. 2009. Glyphosate. p. 589-593. In: „The Pesticide Manual: A World Compedium” (C.D.S. Tomlin, ed.), 9th ed. BCPC Publication, Hapshire, UK, xxii +, 1457 pp.

Ustawa z dnia 25 sierpnia 2006 r. o bezpieczeństwie żywności i żywienia 2006. Dz. U. z 2006 r. Nr 171, poz. 1225: 1-85.

Yenish J.P., Young F.L. 2000. Effect of preharvest glyphosate application on seed and seedling quality of spring wheat (Triticum aestivum). Weed Technology 14 (1): 212-217. 